\title{
The impact of a single episode of remote ischemic preconditioning on myocardial injury after elective percutaneous coronary intervention
}

\author{
Mustafa A. Yılmaztepe ${ }^{1}$, Gökay Taylan ${ }^{1}$, Meryem Aktoz ${ }^{1}$, Hanefi Y. Gürlertop ${ }^{1}$, Yüksel Aksoy ${ }^{1}$, Fatih Özçelik ${ }^{1}$, \\ Kenan Yalta ${ }^{1}$, Galip Ekuklu \\ ${ }^{1}$ Department of Cardiology, School of Medicine, Trakya University, Edirne, Turkey \\ ${ }^{2}$ Department of Public Health, School of Medicine, Trakya University, Edirne, Turkey
}

Adv Interv Cardiol 2017; 13, 1 (47): 39-46

DOI: https://doi.org/10.5114/aic.2017.66185

\begin{abstract}
A bstract
Introduction: Myocardial injury after percutaneous coronary intervention $(\mathrm{PCI})$ occurs in approximately $30 \%$ of procedures, and is related to worse prognosis. Effects of remote ischemic preconditioning (RIPC) on reperfusion injury have been investigated before, yielding conflicting results.

Aim: To assess the impact of a single episode of RIPC on myocardial injury after elective PCI.

Material and methods: One hundred and four patients undergoing elective $\mathrm{PCl}$, with normal baseline cardiac troponin-I (cTn-I) values, were randomized to two groups. Two patients were excluded due to data loss, and 102 patients were analyzed. Five minutes of ischemic preconditioning was delivered just before the intervention to the preconditioning group, by inflating the blood pressure cuff up to $200 \mathrm{~mm} \mathrm{Hg}$ on the non-dominant arm. Postprocedural $16^{\text {th }}$ hour cTn-I, $\Delta \mathrm{cTn}$-I (difference between the $16^{\text {th }} \mathrm{h}$ and baseline cTn-I values) and the prevalence of type 4a myocardial infarction were compared between the two groups.

Results: Median cTn-I values after the procedure were compared. $16^{\text {th }}$ hour CTn-I was insignificantly lower in the preconditioning $\operatorname{arm}(0.026 \mu \mathrm{g} / \mathrm{l}$ vs. $0.045 \mu \mathrm{g} / \mathrm{l}, p=0.186)$. The incidence of $\mathrm{cTn}$-I elevation 5 -fold above the upper reference limit $(\mathrm{URL})(>0.115 \mu \mathrm{g} / \mathrm{l})$ was lower in the preconditioning group, but it was also not significant ( $21.6 \%$ vs. $11.8 \%, p=0.184)$.
\end{abstract}

Conclusions: A single episode of RIPC before elective PCI demonstrated less troponin elevation but failed to show a significant effect.

Key words: percutaneous coronary intervention, remote ischemic preconditioning, myocardial injury.

\section{Introduction}

Percutaneous coronary intervention (PCI) associated with myocardial enzyme elevation occurs in about 30\% of interventions [1, 2]. Although its clinical significance is controversial, it has been shown that even minor troponin elevations might be related to irreversible myocardial necrosis $[3,4]$. Myocardial injury after $\mathrm{PCl}$ can occur due to side branch occlusion, distal embolization, and ischemia/ reperfusion injury $[2,5]$. Remote ischemic preconditioning (RIPC) has been demonstrated to prevent $\mathrm{PCl}$-associated myocardial injury in ST segment elevation myocardial infarction (STEMI) and elective PCI cases [6]. Three cycles of ischemia (each lasting $5 \mathrm{~min}$ ) preceding reperfusion were demonstrated to be beneficial in elective $\mathrm{PCl}$, and this effect was still observed after 6 years, with lower major cardiovascular and cerebral events (MACCE) in the precon- ditioning arm [7, 8]. However, since 3 cycles of ischemia and reperfusion are somewhat time-consuming, it is not practical to apply this technique, especially in ad-hoc $\mathrm{PCl}$ cases or in every patient before diagnostic angiography. There are limited data about the effects of a single episode of ischemic preconditioning. Ischemic preconditioning has been shown to be an all-or-nothing phenomenon $[9,10]$, but it has also been shown that additional cycles of preconditioning could be more effective [11]. A recent study investigated the effect of one cycle of RIPC before elective $\mathrm{PCl}$, and demonstrated its beneficial effects [12].

\section{Aim \\ In this single-center, randomized, prospective study we planned to investigate the effect of a single episode of RIPC on troponin elevation after elective PCI.}




\section{Material and methods}

Patients aged between 18 and 80 years of age, with a diagnosis of stable atherosclerotic heart disease primarily admitted to undergo elective coronary angiography between April 2015 and February 2016, were assessed for eligibility. The exclusion criteria were presence of 1) acute coronary syndrome, 2) left main disease, 3) baseline cardiac troponin-I (cTn-I) elevation (>0.023 $\mu \mathrm{g} / \mathrm{l})$, 4) hemodynamic instability, 5) renal failure (a glomerular filtration rate (GFR) below or equal to a threshold value of $60 \mathrm{ml} / \mathrm{min} / 1.73 \mathrm{~m}^{2}$ ), 6) glibenclamide or nicorandil use, 7) contraindication to cuff inflation in upper extremities (lymphoedema, fistula), 8) suspicion of pregnancy. Patients who did not give written informed consent were not enrolled in the study.

The study was approved by the Local Ethics Committee and was registered in the clinicaltrials.gov database. The study was conducted in accordance with the Declaration of Helsinki.

Three hundred and twenty-six patients undergoing coronary angiography were assessed for eligibility. Eighty-four patients were excluded because of high baseline cTn-I values or renal failure or for refusing to participate, and 138 patients were excluded after coronary angiography (did not receive $\mathrm{PCl}$ ). Eligible patients were randomly allocated to groups. To prevent selection bias the randomization was performed by a third person who was blinded to the clinical information of the patients. A total of 104 patients were randomized. Two patients (one in each group) were excluded from the analysis, since post- $\mathrm{PCl}$ troponin values were missing. Data of 51 patients in the preconditioning group and 51 in the control group (total 102) were analyzed.

All patients were already using acetylsalicylic acid before coronary angiography. $600 \mathrm{mg}$ of clopidogrel was given before $\mathrm{PCl}$ unless the patient was already using a P2Y12 inhibitor. A $70 \mathrm{lU} / \mathrm{kg}$ intravenous bolus of unfractionated heparin (UFH) was given to all patients after femoral sheath insertion and additional UFH was administered to maintain the activated clotting time $>250 \mathrm{~s}$, if needed. All patients had blood pressure cuffs around their arm, but it was inflated to $200 \mathrm{~mm} \mathrm{Hg}$ for $5 \mathrm{~min}$ in the preconditioning group only. The guiding catheter was advanced one minute after cuff deflation. Coronary intervention was performed according to the operator's discretion.

Systolic and diastolic blood pressure and heart rate during stent implantation, presence of chest pain and ST deviation on ECG monitor, lesion characteristics on angiography, predilatations, postdilatations, stent sizes, final angiographic results, and complications were all recorded. Target vessel lesions were classified according to the American Heart Association/American College of Cardiology lesion classification [13]. Pre- and post-procedural thrombolysis in myocardial infarction (TIMI) flow [14] was assessed by two independent operators, blinded to the troponin results and assigned study group of the patient.

To estimate the magnitude of the myocardium at risk, the Alberta Provincial Project for Outcome Assessment in Coronary Heart Diseases (APPROACH) [15] lesion score was used.

Sample size was determined according to the previous studies that showed a reduction in the prevalence of cTn-I elevation achieved by RIPC. While Zografos et al. [12] showed about 23\% reduction, Hoole et al. [7] demonstrated $18 \%$ reduction. We assumed that a $20 \%$ percent reduction by RIPC would be clinically meaningful, and thus 88 patients would be enough to allow such a reduction to be significant $(\alpha=0.05 ; \beta=0.2$; statistical power $=80 \%$ ).

\section{Laboratory measurement}

Following a 12-hour fasting period, blood samples were collected before the procedure. cTn-I was measured before and at the $16^{\text {th }} \mathrm{h}$ after the intervention. CTn-I was analyzed from lithium-heparinised plasma with the AQT90 FLEX Tnl immunoassay (Radiometer Medical ApS, Denmark). The limit of detection has been determined to be $0.0095 \mu \mathrm{g} / \mathrm{l}$. The reportable range of the assay is $0.010-50 \mu \mathrm{g} / \mathrm{l}$. The upper $99^{\text {th }}$ percentile upper reference limit (URL) has been determined to be $\leq 0.023 \mu \mathrm{g} / \mathrm{l}$. Values below $0.01 \mu \mathrm{g} / \mathrm{l}$ were accepted as 0 .

\section{Statistical analysis}

Statistical analysis was performed using IBM SPSS (IBM SPSS Statistics for Windows, Version 20.0 Armonk, NY, IBM Corp). Continuous variables (heart rate, systolic and diastolic blood pressure, etc.) were summarized as mean, standard deviation, minimum, maximum, and median, and compared using Student's $t$ test or the Mann-Whitney $U$ test when appropriate. Categorical data (target vessel, lesion type etc.) were expressed as numbers and percentages and compared using the $\chi^{2}$ test. A value of $p<0.05$ was accepted as significant.

\section{Results}

One hundred four patients were randomized. Two patients (one from each group) were excluded from the analysis because of missing post-PCI blood samples. The $\mathrm{PCl}$ was successfully performed in all randomized patients. With the exception of 2 patients in the preconditioning group all patients underwent stent implantation; in-stent balloon angioplasty was preferred in these $2 \mathrm{pa}$ tients.

\section{Baseline demographic and clinical characteristics}

There were no significant differences between the two groups with regards to sex, age and risk factors of atherosclerosis, renal functions, and medications used. 
Six patients in the control group and 4 patients in the preconditioning group had exercise-induced angina in the last $24 \mathrm{~h}$ but none of the patients had angina in the last $12 \mathrm{~h}(p=0.505)$ (Table I).

\section{Procedural characteristics}

There were no procedural differences between the two groups. The procedural blood pressure values (systolic and diastolic) and heart rates were similar in the two groups. The two groups also did not differ significantly with regards to predilatation times and numbers, postdilatation times and numbers, total dilatation time and number, or stent size and stent numbers. Lesion type, bifurcation procedure, and APPROACH score were also similar between the two groups (Table II).

Baseline and post-PCl $16^{\text {th }} \mathrm{h}$ cTn-I values are shown in Figure $1.16^{\text {th }} \mathrm{h}$ cTn-I values were lower in the preconditioning group, but the difference was not significant (0.032 $\mu \mathrm{g} / \mathrm{l}$ vs. $0.057 \mu \mathrm{g} / \mathrm{l}, p=0.186) . \Delta c \mathrm{Tn}-\mathrm{I}$ (difference between the $16^{\text {th }} \mathrm{h}$ and baseline cTn-I values) was also compared. $\Delta c T n-I$ was lower in the preconditioning group, but the difference was not significant $(0.045 \mu \mathrm{g} / \mathrm{l}$ (interquartile range: $0.013-0.099)$ vs. $0.026 \mu \mathrm{g} / \mathrm{l}$ (interquartile range: $0.011-0.057), p<0.096)$.

The prevalence of patients with cTn-I above the upper reference limit (URL) $(>0.023 \mu \mathrm{g} / \mathrm{l})$ and $\mathrm{cTn}$-I elevation 5 -fold above the URL ( $>0.115 \mu \mathrm{g} / \mathrm{l})$ was lower in the preconditioning group, but the differences were also not significant (cTn-I > URL; $64.7 \%$ vs. $72.5 \%, p=0.160$, cTn-I $>5 \times$ URL; $21.6 \%$ vs. $11.8 \%, p=0.184$ ) (Figure 2).

\section{Discussion}

The present study demonstrated that single cycle RIPC just before elective PCI may have favorable effects on reducing post- $\mathrm{PCl}$ troponin elevation, but failed to show a statistically significant difference.

The rate of $\mathrm{PCl}$ related myocardial injury varies according to the biomarker and cut-off value chosen. In

Table I. Demographic and clinical data of patients

\begin{tabular}{|c|c|c|c|}
\hline Variable & Controls $(n=51)$ & Preconditioning $(n=51)$ & $P$-value \\
\hline \multicolumn{4}{|l|}{ Demographics: } \\
\hline Age [years] & $60.9 \pm 10.8$ & $57.7 \pm 8.9$ & 0.1 \\
\hline Female/male, $n / n$ & $13 / 38$ & $13 / 38$ & 1 \\
\hline \multicolumn{4}{|l|}{ Risk factors: } \\
\hline Hypertension, $n(\%)$ & $42(82.4)$ & $47(92.2)$ & 0.138 \\
\hline Hyperlipidemia, $n$ (\%) & $44(86.3)$ & $44(86.3)$ & 1 \\
\hline Family history, $n$ (\%) & $7(13.7)$ & $15(29.4)$ & 0.054 \\
\hline Smokers, $n(\%)$ & $35(68.6)$ & $33(64.7)$ & 0.674 \\
\hline Diabetes mellitus, $n$ (\%) & $15(29.4)$ & $16(31.4)$ & 0.830 \\
\hline BMI [kg/m²] & $28.55 \pm 4.82$ & $29.07 \pm 4.24$ & 0.563 \\
\hline \multicolumn{4}{|l|}{ Clinical features: } \\
\hline LVEF (\%) & $58.68 \pm 8.94$ & $58.11 \pm 7.54$ & 0.729 \\
\hline GFR $\left[\mathrm{ml} / \mathrm{min} / 1.73 \mathrm{~m}^{2}\right]$ & $91.3 \pm 19.1$ & $89.5 \pm 16.7$ & 0.613 \\
\hline $\operatorname{cCS} 2 / 3, n / n$ & $18 / 33$ & $30 / 21$ & 0.017 \\
\hline Previous MI, $n(\%)$ & $10(19.6)$ & $11(21.6)$ & 0.807 \\
\hline Previous CABG-O, $n(\%)$ & $3(5.9)$ & $3(5.9)$ & 1 \\
\hline Last 24-hour angina, $n(\%)$ & $6(11.8)$ & $4(7.8)$ & 0.505 \\
\hline \multicolumn{4}{|l|}{ Medications, $n(\%)$ : } \\
\hline$\beta$-blockers & $48(94.1)$ & $48(94.1)$ & 1 \\
\hline ACEI/ARB & $39(76.5)$ & $40(78.4)$ & 0.813 \\
\hline Ca-channel blocker & $9(17.6)$ & $10(19.6)$ & 0.799 \\
\hline Statins & $37(72.5)$ & $36(70.6)$ & 0.826 \\
\hline
\end{tabular}

ACEI - angiotensin-converting enzyme inhibitor, ARB - angiotensin II receptor blocker, BMI - body mass index, CCS - Canadian Cardiology Society, CABG-O - coronary artery bypass graft operation, GFR - glomerular filtration rate, LVEF-left ventricular ejection fraction, MI - myocardial infarction. 
Table II. Angiographic and procedural data of patients

\begin{tabular}{|c|c|c|c|}
\hline Variable & Controls $(n=51)$ & Preconditioning $(n=51)$ & $P$-value \\
\hline \multicolumn{4}{|l|}{ Angiographic parameters: } \\
\hline Target vessel, $n(\%)$ & & & 0.400 \\
\hline LAD & 17 & 19 & \\
\hline $\mathrm{LCX}$ & 5 & 9 & \\
\hline RCA & 19 & 18 & \\
\hline Combined/other & 10 & 5 & \\
\hline Lesion AHA/ACC, $n$ (\%) & & & 0.746 \\
\hline Type A & $8(15.7)$ & $11(21.6)$ & \\
\hline Type B & $25(49)$ & $23(45.1)$ & \\
\hline Type C & $18(35.3)$ & $17(33.3)$ & \\
\hline APPROACH score (\%) & $28.15 \pm 13.26$ & $25.65 \pm 11.99$ & 0.321 \\
\hline Stenosis severity (\%) & $81.7 \pm 9.6$ & $81.5 \pm 91.3$ & 0.891 \\
\hline$\geq 2$ mm side branch, $n(\%)$ & $13(25.5)$ & $8(15.7)$ & 0.221 \\
\hline TIMI flow 0-2, n (\%) & $7(13.7)$ & $3(5.8)$ & 0.183 \\
\hline \multicolumn{4}{|l|}{ Procedural data: } \\
\hline Heart rate [beats/min] & $77.45 \pm 10.89$ & $74.19 \pm 9.43$ & 0.110 \\
\hline Systolic blood pressure [mm Hg] & $138.37 \pm 15.03$ & $140.7 \pm 18.85$ & 0.491 \\
\hline Diastolic blood pressure [mm Hg] & $77.54 \pm 7.41$ & $75.96 \pm 8.11$ & 0.305 \\
\hline Procedural angina, $n(\%)$ & $26(51)$ & $24(47.1)$ & 0.692 \\
\hline Procedural ST deviation, $n$ (\%) & $16(31.4)$ & $13(25.5)$ & 0.510 \\
\hline Bifurcation procedure, $n(\%)$ & $3(5.8)$ & $4(7.8)$ & 0.603 \\
\hline DES/BMS/Balloon, $n / n / n$ & $46 / 5 / 0$ & $48 / 1 / 2$ & 0.095 \\
\hline Stent length [mm] & $27.17 \pm 13.79$ & $26.12 \pm 11.88$ & 0.684 \\
\hline Stent number & $1.31 \pm 0.55$ & $1.17 \pm 0.52$ & 0.196 \\
\hline Stent diameter [mm] & $2.85 \pm 0.4$ & $2.83 \pm 0.39$ & 0.841 \\
\hline Total dilatation time $[\mathrm{s}]$ & $74.25 \pm 55.5$ & $81.4 \pm 44.6$ & 0.476 \\
\hline Predilatation, $n(\%)$ & $20(39.2)$ & $22(43.1)$ & 0.687 \\
\hline Postdilatation, $n(\%)$ & $31(60.8)$ & $33(64.7)$ & 0.682 \\
\hline Predilatation time [s] & $33.57 \pm 34.17$ & $25.35 \pm 19.76$ & 0.355 \\
\hline Postdilatation time $[\mathrm{s}]$ & $43.61 \pm 27.78$ & $48.47 \pm 25.52$ & 0.458 \\
\hline Total dilatation number & $3.6 \pm 2.8$ & $3.7 \pm 2.3$ & 0.845 \\
\hline Cuff deflation to stent implantation time [s] & - & $432.9 \pm 221.1$ & \\
\hline \multicolumn{4}{|l|}{ Post-PCI results: } \\
\hline TIMI flow $2 / 3, n / n$ & $0 / 51$ & $2 / 49$ & 0.153 \\
\hline Dissection & 0 & 0 & 1 \\
\hline Death & 0 & 0 & 1 \\
\hline TIMI flow 0-2 at side branch & 0 & 0 & 1 \\
\hline
\end{tabular}

$B M S$ - bare metal stent, DES - drug-eluting stent, $L A D$ - left anterior descending artery, $L C X$ - left circumflex artery, RCA - right coronary artery, PCI - percutaneous coronary intervention, TIMI - thrombolysis in myocardial infarction. 
A

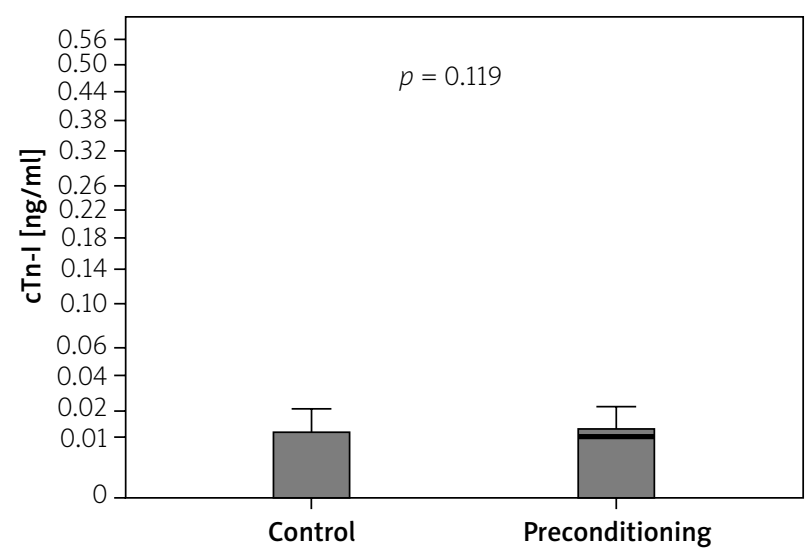

B

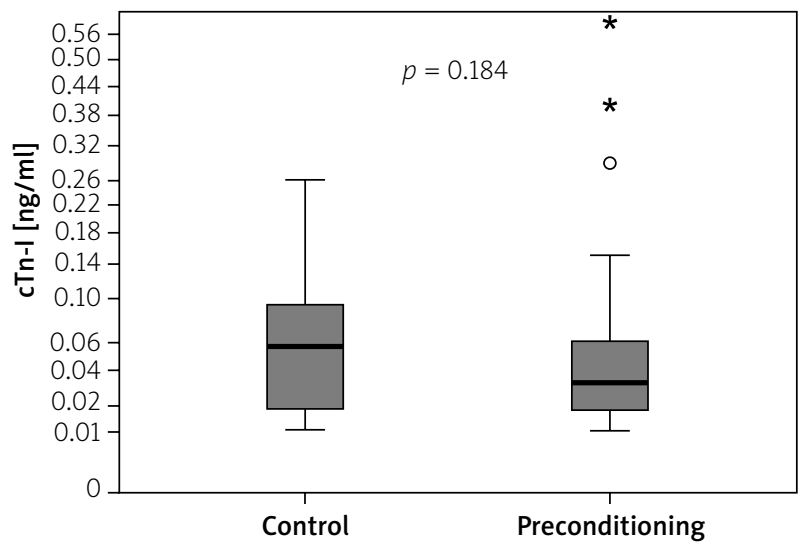

Figure 1. Median (interquartile range) cardiac troponin-I (cTn-I) values at baseline (A) and $16 \mathrm{~h}$ after $\mathrm{PCI}(\mathbf{B})$. The $25^{\text {th }}$ and $75^{\text {th }}$ percentiles are indicated by the shaded box. The line within the box represents the median value

a recently published article mild to moderate periprocedural myocardial injury was detected in $49.8 \%$ of the patients and severe myocardial injury was detected in $12.2 \%$ of the patients [16]. Some authors argue that high-sensitivity troponin measurement after $\mathrm{PCl}$ can be over-diagnostic; however, it has also been shown that patients with higher troponin levels have worse prognosis $[4,17]$. Although there is controversy about the cut-off values for troponin and creatinine kinase (CK)-MB in the determination of $\mathrm{PCl}$-related myocardial infarction [18], the third Universal Definition of Myocardial Infarction Guideline [19] recommended troponin measurement after $\mathrm{PCl}$ and defined myocardial infarction after $\mathrm{PCl}$ (type $4 a \mathrm{MI}$ ) as a 5 -fold increase of troponin with clinical or electrocardiographic evidence. Solely troponin elevation above the URL, or values 5 -fold above the URL without clinical or ECG findings, is defined as myocardial injury. Myocardial injury after $\mathrm{PCl}$ is due to microembolization of small debris, side branch occlusion, or ischemia/reperfusion injury.

Remote ischemic preconditioning has been investigated in several studies in an effort to obviate ischemia/ reperfusion injury of the myocardium. Ischemic preconditioning was first demonstrated by Murry et al., by applying four cycles of intermittent nonlethal ischemia and reperfusion to the left anterior descending artery of a canine heart, which resulted in a $75 \%$ reduction in infarct size in the preconditioning group [20]. Przyklenk et al. first reported that ischemia in a remote organ could also protect the myocardium against ischemia [21], and later in 2002 Kharbanda et al. showed the beneficial effects of RIPC in human subjects [22]. Further RIPC studies have been performed in STEMI, in cardiac surgery and in elective $\mathrm{PCl}$ cases [7, 8, 23-26].

The exact mechanism underlying the protective effect of RIPC on reperfusion injury is not fully understood yet. Although RIPC has promising effects, there are limited data about its effects in planned $\mathrm{PCl}$. Different protocols,

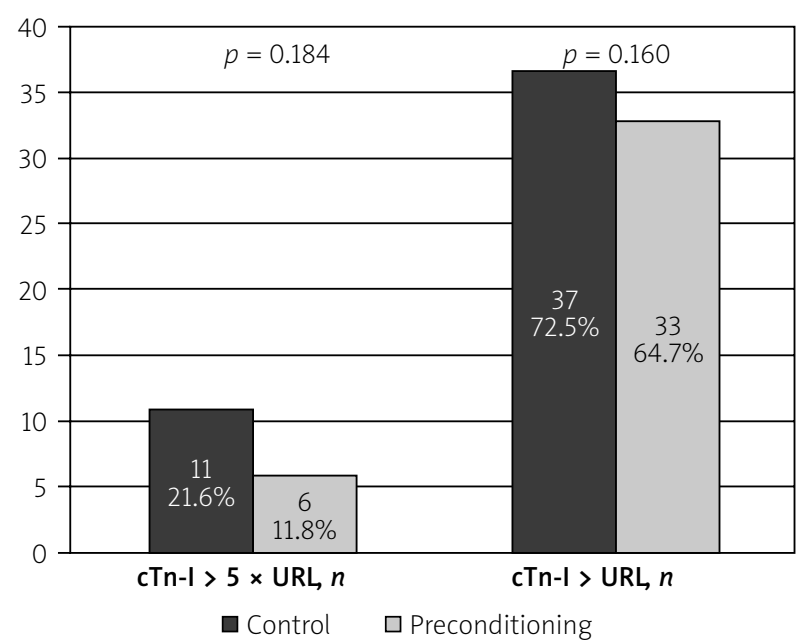

Figure 2. Prevalence of cardiac troponin-I (cTn-I) above upper reference limit (URL) and above $5 \times \mathrm{URL}$

to test the possible protective effects of RIPC, were chosen in the previous studies [7, 12, 25-30]. The study by Iliodromitis et al. was the first to investigate the effect of RIPC in elective $\mathrm{PCI}$ [25]. In that study, 41 patients (20 in the RIPC group and 21 controls) were enrolled, and $3 \mathrm{cy}$ cles of 5-minute ischemia were administered to bilateral arms; as a result no cardioprotection was achieved. Moreover, troponin release was exacerbated in the RIPC group. Hoole et al. demonstrated that 3 cycles of 5-minute RIPC administered before planned $\mathrm{PCl}$ diminished $\mathrm{PCl}$-related myocardial injury, but did not demonstrate an effect on the prevalence of type 4a MI [7]. In the study of Ahmed et al., although there was less procedure-related $\mathrm{MI}$ in the preconditioning group, the difference did not reach statistical significance; but the authors also demonstrated attenuated troponin release [27]. In contrast to these 2 studies, Luo et al. were able to achieve 15\% fewer type 4a MIs in the RIPC group (39\% vs. 54\%, $p=0.029$ ) [26]. Prasad et al. [28] used a different protocol and delivered 
3 cycles of 3-minute ischemia/reperfusion immediately before $\mathrm{PCl}$, but they were not able to show cardioprotection. Unlike the studies of classical preconditioning, Liu et al. demonstrated that late RIPC also had beneficial effects on patients undergoing elective $\mathrm{PCl}$ [29]. Although there is heterogeneity in RIPC protocols, meta-analyses of the major RIPC studies in elective $\mathrm{PCl}$ indicated that ischemic preconditioning had beneficial effects on post$\mathrm{PCl}$ myocardial injury [31-33].

The RIPC is a simple, cheap and practical technique, but the optimal protocol to achieve the most effective cardioprotection has not yet been demonstrated. There are controversies about the number of cycles, ischemia duration and the limbs used for ischemia. Different protocols have been investigated to minimize the delay of intervention and to improve practicality because 3 cycles of 5-minute RIPC are rather time-consuming and ad-hoc $\mathrm{PCl}$ is more commonly performed. In a study by Ghaemian et al. 2 cycles of 5-minute ischemia/reperfusion were administered to the lower limb, which revealed a $27.5 \%$ reduction in $\mathrm{PCl}$-related myonecrosis [34]. Prasad et al. [28] induced 3 cycles of 3-minute RIPC, to shorten the duration of preconditioning, but, consistent with the study of Iliodromitis et al. [25], they failed to achieve cardioprotection. One possible reasons for this negative effect was attributed to the shorter duration of ischemia, which implies that 3 min of cuff inflation might not generate sufficient preconditioning.

In the present study, we performed a single episode of 5-minute ischemia. The number of cycles has been investigated in various studies, and the results were conflicting. In their study of ischemic preconditioning, Li et al. stated that preconditioning was an all-or-nothing phenomenon and demonstrated that cardioprotection could be achieved with one cycle of ischemia [9]. In an animal study by Lu et al. one cycle of preconditioning did not provide protection, but 3 cycles of ischemia did [35]. Further studies also showed that supplementary cycles could achieve more protection $[10,36]$. A recently published animal study compared the effects of the number of cycles of RIPC, duration of ischemia, and one or two hind-limb ischemia on ischemia/reperfusion injury [37]. Two, 4, 6 and 8 cycles of ischemia (each lasting $5 \mathrm{~min}$ ) preceding reperfusion were compared; 2 cycles of RIPC were found ineffective. The authors concluded that the number of cycles and duration of ischemia were the major determinants of efficient preconditioning. Zografos et al. were the first to assess the effect of one cycle of RIPC on elective PCI [12]. Unlike our study, they were able to demonstrate significant reduction in the prevalence of type $4 \mathrm{a} \mathrm{MI}(42.6 \%$ vs. $19.1 \%, p=0.014)$ and in cTn-I $(0.04 \mu \mathrm{g} / \mathrm{l}$ vs. $0.19 \mu \mathrm{g} / \mathrm{l}, p<0.001)$. The most remarkable difference of the Zografos et al. study compared with the present study is the higher prevalence of type $4 \mathrm{a} \mathrm{MI}(42.6 \%$ vs. $21.6 \%)$, which can be explained by the higher rate of complications and higher APPROACH score. With the exception that the percentage of patients with diabetes was lower in the study of Zografos et al., the sample size and study population were similar in both studies (21\% vs. $31 \%)$. The presence of DM could attenuate the protective effects of RIPC [30]. The diabetic group in our study constituted about one third of the study population, without a significant difference between groups. In the Hoole et al. and Zografos et al. studies the percentage of diabetic patients was about $20 \%$, whereas about $30 \%$ of the Ahmed et al. and Luo et al. studies were diabetic; all were able to achieve positive results with RIPC. As with the previous studies, the present study was also underpowered to investigate the effect of these factors on RIPC.

The time between the cuff deflation and stent implantation can also be argued as a cause for the discrepancies between the previous studies with 3 cycles of ischemia. However, classical conditioning as we applied is described as preconditioning within $3 \mathrm{~h}$ of the ischemic event, and its effect starts immediately and vanishes in about 2-3 h [38]. We delivered 5 min of RIPC just before the $\mathrm{PCl}$. The mean cuff deflation to stent implantation time was $432.9 \pm 221.1$ s. Zografos et al. achieved positive results with a shorter time between cuff deflation and stent implantation.

One can argue that the control group might also gain benefit from pre- or post-conditioning due to predilatations or postdilatations during $\mathrm{PCl}$. With this study we tried to show the effect of RIPC in real-life clinical practice. The comparison of procedural data (balloon dilatations, duration and number) between the two groups were found similar, so this could not have a significant effect.

\section{Limitations of the study}

One of the major limitations of our study is the small sample size. The results might be different with a larger sample size, and the difference between the groups might be more significant. The other major limitation is that we used cTn-I to detect myocardial injury. Although guidelines recommended cTn-I for the detection of type 4a MI, it may be over-diagnostic and not clinically important. Troponin elevation after PCl occurs between 12 and 24 h. As such serial cTn-I measurements would be more sensitive in detecting the magnitude of myocardial injury. By taking a single blood sample at the $16^{\text {th }} \mathrm{h}$ of the intervention, we might have missed the maximum concentration. Long-term follow-up and magnetic resonance imaging could have given us more objective data about post- $\mathrm{PCl}$ myocardial injury and its clinical relevance.

\section{Conclusions}

Remote ischemic preconditioning is a promising technique for reducing $\mathrm{PCl}$-related myocardial injury. Due to the lack of homogeneity of the previous studies, the optimum protocol has not yet been standardized. Although 
we were able to demonstrate less cTn-I elevation with one cycle of RIPC, we could not show a statistically significant reduction, indicating that one cycle of RIPC might not generate adequate preconditioning. Further randomized, prospective, multi-center, larger scale studies with a long follow-up are needed to determine the most effective RIPC model.

\section{Conflict of interest}

The authors declare no conflict of interest.

\section{References}

1. Babu GG, Walker JM, Yellon DM, et al. Peri-procedural myocardial injury during percutaneous coronary intervention: an important target for cardioprotection. Eur Heart J 2011; 32: 23-31.

2. Herrmann J. Peri-procedural myocardial injury: 2005 update. Eur Heart J 2005; 26: 2493-519.

3. Selvanayagam JB, Porto I, Channon K, et al. Troponin elevation after percutaneous coronary intervention directly represents the extent of irreversible myocardial injury: insights from cardiovascular magnetic resonance imaging. Circulation 2005; 111: 1027-32.

4. Liou K, Jepson N, Kellar P, et al. Prognostic significance of peri-procedural myocardial infarction in the era of high sensitivity troponin: a validation of the Joint ACCF/AHA/ESC/WHF Universal Definition of Type 4a Myocardial Infarction with High Sensitivity Troponin T. Heart Lung Circ 2015; 24: 673-81.

5. Heusch G, Kleinbongard P, Bose D, et al. Coronary microembolization: from bedside to bench and back to bedside. Circulation 2009; 120: 1822-36.

6. Heusch G, Botker HE, Przyklenk K, et al. Remote ischemic conditioning. J Am Coll Cardiol 2015; 65: 177-95.

7. Hoole SP, Heck PM, Sharples L, et al. Cardiac Remote Ischemic Preconditioning in Coronary Stenting (CRISP Stent) Study: a prospective, randomized control trial. Circulation 2009; 119: 820-7.

8. Davies WR, Brown AJ, Watson W, et al. Remote ischemic preconditioning improves outcome at 6 years after elective percutaneous coronary intervention: the CRISP stent trial long-term follow-up. Circ Cardiovasc Interv 2013; 6: 246-51.

9. Li GC, Vasquez JA, Gallagher KP, et al. Myocardial protection with preconditioning. Circulation 1990; 82: 609-19.

10. Goto M, Liu Y, Yang XM, et al. Role of bradykinin in protection of ischemic preconditioning in rabbit hearts. Circ Res 1995; 77: 611-21.

11. Schulz R, Post H, Vahlhaus C, et al. Ischemic preconditioning in pigs: a graded phenomenon: its relation to adenosine and bradykinin. Circulation 1998; 98: 1022-9.

12. Zografos TA, Katritsis GD, Tsiafoutis I, et al. Effect of one-cycle remote ischemic preconditioning to reduce myocardial injury during percutaneous coronary intervention. Am J Cardiol 2014; 113: 2013-7.

13. Ryan TJ, Faxon DP, Gunnar RM, et al. Guidelines for percutaneous transluminal coronary angioplasty. A report of the American College of Cardiology/American Heart Association Task Force on Assessment of Diagnostic and Therapeutic Cardiovascular Procedures (Subcommittee on Percutaneous Transluminal Coronary Angioplasty). Circulation 1988; 78: 486-502.

14. Ganz W. The thrombolysis in myocardial infarction (TIMI) trial. N Engl J Med 1985; 313: 1018.
15. Graham MM, Faris PD, Ghali WA, et al. Validation of three myocardial jeopardy scores in a population-based cardiac catheterization cohort. Am Heart J 2001; 142: 254-61.

16. Buturak A, Degirmencioglu A, Surgit O, et al. Rise of serum troponin levels following uncomplicated elective percutaneous coronary interventions in patients without clinical and procedural signs suggestive of myocardial necrosis. Adv Interv Cardiol 2016; 12: 41-8.

17. Feldman DN, Kim L, Rene AG, et al. Prognostic value of cardiac troponin-I or troponin-T elevation following nonemergent percutaneous coronary intervention: a meta-analysis. Catheter Cardiovasc Interv 2011; 77: 1020-30.

18. Moussa ID, Klein LW, Shah B, et al. Consideration of a new definition of clinically relevant myocardial infarction after coronary revascularization: an expert consensus document from the Society for Cardiovascular Angiography and Interventions (SCAI). J Am Coll Cardiol 2013; 62: 1563-70.

19. Thygesen K, Alpert JS, Jaffe AS, et al. Third universal definition of myocardial infarction. Eur Heart J 2012; 33: 2551-67.

20. Murry CE, Jennings RB, Reimer KA. Preconditioning with ischemia: a delay of lethal cell injury in ischemic myocardium. Circulation 1986; 74: 1124-36.

21. Przyklenk K, Bauer B, Ovize M, et al. Regional ischemic 'preconditioning' protects remote virgin myocardium from subsequent sustained coronary occlusion. Circulation 1993; 87: 893-9.

22. Kharbanda RK, Mortensen UM, White PA, et al. Transient limb ischemia induces remote ischemic preconditioning in vivo. Circulation 2002; 106: 2881-3.

23. Hausenloy DJ, Candilio L, Evans R, et al. Remote ischemic preconditioning and outcomes of cardiac surgery. N Engl J Med 2015; 373: 1408-17.

24. Ahmad AM, Ali GS, Tariq W. Remote ischemic preconditioning is a safe adjuvant technique to myocardial protection but adds no clinical benefit after on-pump coronary artery bypass grafting. Heart Surg Forum 2014; 17: E220-3.

25. Iliodromitis EK, Kyrzopoulos S, Paraskevaidis IA, et al. Increased $C$ reactive protein and cardiac enzyme levels after coronary stent implantation. Is there protection by remote ischaemic preconditioning? Heart 2006; 92: 1821-6.

26. Luo SJ, Zhou YJ, Shi DM, et al. Remote ischemic preconditioning reduces myocardial injury in patients undergoing coronary stent implantation. Can J Cardiol 2013; 29: 1084-9.

27. Ahmed RM, Mohamed el HA, Ashraf M, et al. Effect of remote ischemic preconditioning on serum troponin $\mathrm{T}$ level following elective percutaneous coronary intervention. Catheter Cardiovasc Interv 2013; 82: E647-53.

28. Prasad A, Gossl M, Hoyt J, et al. Remote ischemic preconditioning immediately before percutaneous coronary intervention does not impact myocardial necrosis, inflammatory response, and circulating endothelial progenitor cell counts: a single center randomized sham controlled trial. Catheter Cardiovasc Interv 2013; 81: 930-6.

29. Liu Z, Wang YL, Hua Q, et al. Late remote ischemic preconditioning provides benefit to patients undergoing elective percutaneous coronary intervention. Cell Biochem Biophys 2014; 70: 437-42.

30. Xu X, Zhou Y, Luo S, et al. Effect of remote ischemic preconditioning in the elderly patients with coronary artery disease with diabetes mellitus undergoing elective drug-eluting stent implantation. Angiology 2014; 65: 660-6.

31. D’Ascenzo F, Moretti C, Omede P, et al. Cardiac remote ischaemic preconditioning reduces periprocedural myocardial infarction 
for patients undergoing percutaneous coronary interventions: a meta-analysis of randomised clinical trials. Eurolntervention 2014; 9: 1463-71.

32. Zografos TA, Katritsis GD, Katritsis DG. Remote ischemic preconditioning reduces peri-procedural myocardial injury in elective percutaneous coronary intervention: a meta-analysis. Int J Cardiol 2014; 173: 530-2.

33. Niu X, Zhang J, Chen D, et al. Remote ischaemic conditioning in percutaneous coronary intervention: a meta-analysis of randomised trials. Postep Kardiol Interw 2014; 10: 274-82.

34. Ghaemian A, Nouraei SM, Abdollahian F, et al. Remote ischemic preconditioning in percutaneous coronary revascularization: a double-blind randomized controlled clinical trial. Asian Cardiovasc Thorac Ann 2012; 20: 548-54.

35. Lu Y, Dong CS, Yu JM, et al. Morphine reduces the threshold of remote ischemic preconditioning against myocardial ischemia and reperfusion injury in rats: the role of opioid receptors. J Cardiothorac Vasc Anesth 2012; 26: 403-6.

36. Sandhu R, Diaz RJ, Mao GD, et al. Ischemic preconditioning: differences in protection and susceptibility to blockade with single-cycle versus multicycle transient ischemia. Circulation 1997; 96: 984-95.

37. Johnsen J, Pryds K, Salman R, et al. The remote ischemic preconditioning algorithm: effect of number of cycles, cycle duration and effector organ mass on efficacy of protection. Basic Res Cardiol 2016; 111: 10.

38. Hausenloy DJ, Yellon DM. Ischaemic conditioning and reperfusion injury. Nat Rev Cardiol 2016; 13: 193-209. 